\title{
Analytical Criteria for Evaluation of Engineering Level of Grain Harvesters
}

\author{
E.V. Zhalnin ${ }^{1}$, V.L. Astafyev ${ }^{2}$, M.E. Chaplygin ${ }^{1}$ \\ ${ }^{1}$ Federal Scientific Agroengineering Center VIM, Moscow, Russia \\ ${ }^{2}$ Kostanay branch of "Scientific Production Center of Agricultural Engineering" LLC, Kostanay, Kazakhstan
}

\begin{abstract}
The most common analytical criterion of evaluation of engineering state of grain harvesters is its net output in terms of threshed crops per unit time $(\mathrm{kg} / \mathrm{s})$ with allowable grain loss: $1.5 \%$. This output is referred to as rated output of threshing machine, determined by operating performance of threshing machine (OPTM) expressed as grain loss by threshing machine as a function of crop feeding. All harvesters are conventionally compared by output, then the use of OPTM is terminated. The harvester classes are defined with certain interval depending on possible combination of each harvester model with certain reaper cutting width and harvester speed. In Russia, this interval equals to $1-2 \mathrm{~kg} / \mathrm{s}$. Therefore, the basic classes of harvesters in terms of output were formed: I: $1 \mathrm{~kg} / \mathrm{s}$; II: $2-3 \mathrm{~kg} / \mathrm{s}$; III: 5-6 kg/s; IV: $7-8 \mathrm{~kg} / \mathrm{s}$; V: $9-10 \mathrm{~kg} / \mathrm{s}$; VI: $11-12 \mathrm{~kg} / \mathrm{s}$, and VII: $13-15 \mathrm{~kg} / \mathrm{s}$. However, due to intensive development of modern manufacture of harvesters, numerous modifications of basic harvesters have appeared, including harvesters with various designs of threshing and separating devices. Their evaluation only by their output became insufficient, especially in the cases when different harvesters were characterized by the same or similar output; during actual operational conditions their results turned to be unpredictable. In this regard, it became necessary to expand the list of evaluations of their engineering level. Five analytical criteria have been proposed.
\end{abstract}

Key words : harvester, engineering level, criteria, loss.

\section{INTRODUCTION}

In order to compare engineering level of various harvesters, to determine their position in terms of dimension range on farm or regional scale and predict their efficiency, the output of threshing machine and harvester is applied. It is determined by operation performance of threshing machine (OPTM) and harvester, which reflects variation of grain loss by harvester as a function of crop feed at certain ratio of straw to grain weight. At standard limitation of grain loss in percent, the crop feed is determined. Then it is adjusted depending on amount of straw and crushed grains. After that, this feed is referred to as reduced and it is used for determination of harvester output in $\mathrm{kg} / \mathrm{s}$. However, this criterion is insufficient for evaluation of engineering level of modern harvesters. This work is aimed at development of a set of analytical evaluation criteria of engineering level of grain harvesters so that to improve information content about harvester design and to predict quality of their operation under actual conditions.

\section{METHODS}

In accordance with previous works [1-8], OPTM is determined during field tests of a harvester, when actual grain loss by harvester in wheatears (heads) is defined due to incomplete straw separation on separator and screen at each crop feed. Allowable loss, $\boldsymbol{y}$, is fixed on the ordinate, and the respective reduced crop feed, $\boldsymbol{q}_{k}$, is fixed on the abscissa. The obtained set of points is approximated by certain equation using appropriate software. Analysis is performed using linear and nonlinear equations: $\mathrm{y} \approx \mathrm{f}\left(\mathrm{q}_{\mathrm{i}}\right)$. The basic equations are those, which, on the basis of statistic criteria, describe more adequately the experimentally obtained set of the points $\mathrm{y}_{\mathrm{i}}$ and $\mathrm{q}_{\mathrm{i}}$. Then, at preset loss level (1.5\%), at the intersection with the plot $\mathrm{y} \approx \mathrm{f}\left(\mathrm{q}_{\mathrm{i}}\right)$, the value of $\mathrm{q}_{\mathrm{k}}$ is determined which is referred to as output of threshing machine and harvester. Then the use of OPTM is terminated. However, it has been revealed that in the case of further analysis of OPTM using several mathematical procedures, it is possible to obtain valuable information about harvester engineering level, stability of its operation, and to predict grain loss in the course of regular operation. Herewith, these indices are strictly individual, they could be used for more extensive analysis of various harvesters in comparison with that based only on their output. The approximating equation of OPTM was analyzed in wide range of crop feed to threshing machine.

\section{RESULTS AND DISCUSSION}

Depending on the range of crop feed to harvesters, the following equations turned to be the most suitable for description of OPTM: 


$$
\begin{gathered}
\text { linear } y_{i}=a+b g_{i} \\
\text { exponential } \quad y_{i}=a e^{b g_{i}} \\
\text { logistic } y_{i}=\frac{y_{\max }}{1+c \exp \left(-k y_{\max } q_{i}\right)} \\
\text { normalized logistic } \\
y_{i}=\frac{3_{\max }}{1+\left\{c\left(\exp \left(k a y_{\max }\right\}-1\right\}^{-1}\right.}
\end{gathered}
$$

These equations are illustrated in Fig. 1. Exponential integral dependence for OPTM was proposed in [9], where grain loss was presented as a function of total length of threshing and separating units of harvester, being rather varying parameter. Unfortunately, the authors did not provide general view of this dependence.

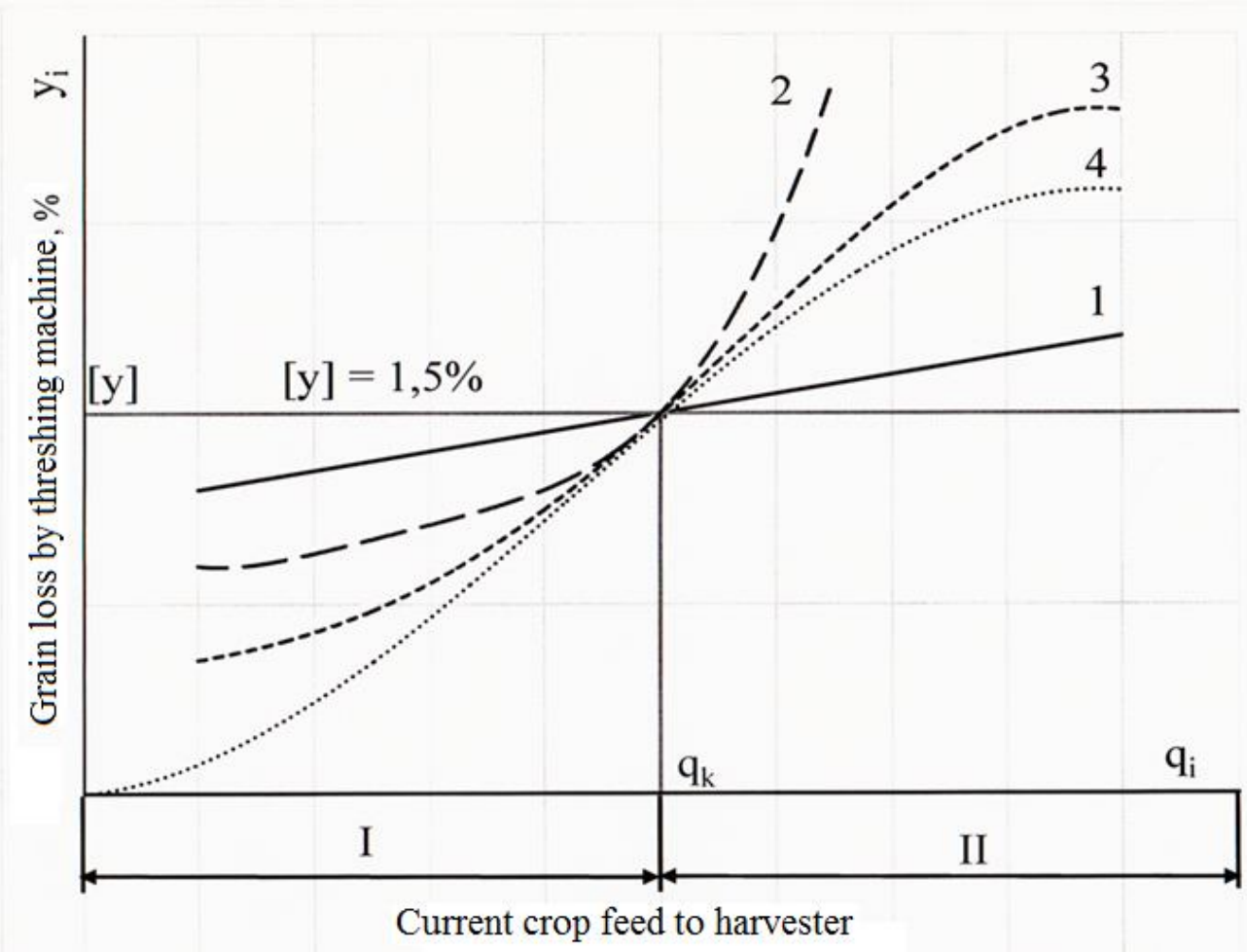

Figure 1: Operation performances of harvesters: 1 - linear dependence, 2 - exponential, 3 - logistic, 4 - normalized logistic; I harvester operation mode, II - overload load.

Linear function (Eq. (1)) is more often applied upon determination of OPTM in narrow range of crop feed: up to 3 $\mathrm{kg} / \mathrm{s}$, as well as for high-performance axial rotary harvesters upon crop feed in the range of $6-15 \mathrm{~kg} / \mathrm{s}$.

Exponential Eq. (2) was the most common for classic harvesters manufactured in 1947-1990, i.e. upon crop feed up to $7-8 \mathrm{~kg} / \mathrm{s}$ [1]. At high feeds, the exponent did not provide adequate results, especially above $8 \mathrm{~kg} / \mathrm{s}$. Moreover, the exponent contradicts with the physical essence of increase in grain loss with crop feed: its right-hand branch has no physical sense. A harvester cannot lose grain in the amount higher than the amount of grain fed for threshing. Thus, the exponent was replaced with the logistic function [10], where the right-hand branch reached natural limit, $100 \%$, when the feed was $\mathrm{g}_{\mathrm{i}}: \rightarrow \infty$. In this case, the logistic function (Eq. (4)) most of all corresponded to the physical essence of threshing and separating in harvester: at $\mathrm{q}_{\mathrm{i}} \rightarrow 0$ and $\mathrm{y}_{\mathrm{i}} \rightarrow 0$, and at $\mathrm{q} \rightarrow$ $\infty, \rightarrow \mathrm{y}_{\max } \rightarrow 100 \%$.
The logistic function (Eq. (3)) is included in the tests of grain harvesters [1], where $y_{i}$ and $q_{i}$ are the current grain loss and the crop feed to harvester; $y_{\max }, c$ and $\mathrm{k}$ are the constants determined upon data processing. At present, the performance of threshing machine and harvester is applied only for determination of their position in terms of dimension range on farm or regional scale according to certain classification. In Russia, the classification step is $1-2 \mathrm{~kg} / \mathrm{s}$. Therefore, seven classes of harvesters are considered: Class I: 1-2 kg/s; Class II: 3-4 kg/s; III: 5-6 kg/s; IV: 7-8 kg/s; V: 9-10 $\mathrm{kg} / \mathrm{s}$; VI: $11-12 \mathrm{~kg} / \mathrm{s}$; VII: $13-15 \mathrm{~kg} / \mathrm{s}$. Depending on regions, crop feed of each harvester class is provided by predetermined ratio of harvester cutting width and harvester speed at actual yield of grain and straw.

However, due to intensive development of world and Russian harvester manufacturing, after 1990 numerous new basic harvesters and their modifications were developed, including with unique types of threshing and separating units, various engine powers, types of actuators, etc. Their integrated 
E.V. Zhalnin et al., International Journal of Emerging Trends in Engineering Research, 8(9), September 2020, $6546-6552$

evaluation could not be obtained only on the basis of output, especially if during comparative tests of various models, they demonstrated the same outputs or with the difference of $5-10 \%$. This required for expanded set of evaluation criteria of harvester performances.

It has been revealed that analysis of OPTM allows to detect new important properties of harvesters, which in their combination make it possible to evaluate more precisely design of any harvester, to compare different models, and to forecast their specifications upon operation under actual conditions. Five new analytical indices have been proposed for evaluation of engineering level of grain harvesters, based on analysis of performances of threshing machine and harvester:

The first index is the output at actual feed but reduced to standard indices of grain loss, straw amount, grain threshing, and straw moisture content. Assumed: allowable grain loss: $1.5 \%$ of threshed grain and collected into tankers; grinding: $2 \%$ for cereals; straw amount: 0.6 ; and straw moisture content: $22 \%$. Such integrated reduction of actual feed to certain reference value makes it possible to compare different harvesters after testing under different conditions. Passport output can be achieved by a harvester more easily (at least with lower energy consumption) in the case of low straw amount, 0.4-0.5, in comparison with 0.7-0.8 and higher. Reducing OPTM to one and the same straw amount (the standard value is 0.6 ) would equalize the conditions for comparative evaluation of harvesters. The same is achieved by reducing in terms of grain grinding, $2 \%$, for cereals with consideration for $0.12-0.15$ of milling loss per each percent of grinding. This variant of reducing mainly depends on testing conditions and existence of specialized equipment, therefore, such reducing is more desirable than obligatory.

Straw with the moisture content above $22 \%$ affects significantly the grain loss. Hence, in such a case, it is obligatory to reduce actual crop feed to harvester to standard moisture content. At present, the standard procedure of harvester testing [1] stipulates reduction of actual feed with regard to straw amount, and only partial reduction is made with regard to grain grinding with consideration for milling loss of ground grain. We recommend obligatory reduction with regard to all four indices including straw moisture content. Such types of reduction of actual feed and determination of OPTM with regard to reduced feed would allow to evaluate more accurately the harvester output.

The actual feed $\mathrm{q}_{\mathrm{act}}$ is converted into the reduced feed with regard to straw amount as follows:

$$
q_{r e d, \alpha}=q_{a c t} \frac{1+\alpha_{a c t}}{1+\alpha_{s t}}
$$

where $\alpha_{\text {act }}$ is the actual ratio of straw weight to grain

weight in initial crop feed to harvester; $\alpha_{s t}=1.5$ is the standard ratio of straw weight to grain weight.
The reduction with regard to straw moisture content, that is, $q_{r e d, \alpha}$ to $q_{r e d, w, \text { is performed as follows: }}$

$$
q_{\text {red }, w}=q_{r e d, \alpha} \frac{100-W_{s t}}{100-W_{\text {rad }}}
$$

Higher straw amount and straw moisture content in comparison with standard values increase predicted harvester output, and lower straw amount and moisture content decrease the output since under difficult conditions of harvesting (the first case), harvester operation is complicated. Grain moisture content in the typical harvesting range of $8-22 \%$ exerts small effect on grain loss [11, 12], and reduction of actual crop feed with regard to this index is not required until achievement of certain additional experimental results. Therefore, the total equation for reduction of actual crop feed to reduced one for determination of OPTM is as follows:

$$
q_{\mathrm{red}}=q_{a c t}\left[\frac{1+\alpha_{a c t}}{1+\alpha_{s t}}\right] *\left[\frac{100-w_{s t}}{100-w_{a r t}}\right]
$$

Thus, we designate the output of reference harvester, reduced to standards with regard to grain loss, grinding, straw amount, straw moisture content as $\mathrm{q}_{\text {ref. }}$. Therefore, for a comparative harvester (for instance, new), we have $\mathrm{q}_{\text {new }}$. Then, the first analytical criterion is defined as follows:

$$
\lambda_{1}=\frac{q_{\text {new }}}{q_{\text {ref }}}
$$

If $\lambda_{1}>1$, then the new harvester is more efficient. If $\lambda_{1}<1$, then the reference harvester is superior.

The second index is the coefficient of increase in intensity of grain loss by harvester with the increase in crop feed. Each harvester is characterized by its individual response to feed and, respectively, by individual intensity of variation of grain loss. This performance evaluates stability of harvester operation, especially if their output is high. This criterion is measured in loss portions per $1 \mathrm{~kg} / \mathrm{s}$ of feed. Its value depends on engine power: to which extent it suits its output, as well as on design and parameters of threshing and separating unit. This criterion cannot be qualitatively evaluated by conventional determination of the function maximum. If we take the derivative and equate it to zero, then the minimum loss is zero, however, if the crop feed is zero, then the harvester operation is absent. Therefore, any equation $\mathrm{y}=\mathrm{f}(\mathrm{q})$ contains the coefficient of increase of intensity of grain loss. In Eq. (1), this is slope angle with respect to abscissa or tangent. In Eqs. (2), (3), (4), this is $\boldsymbol{k} \boldsymbol{b}$ at $\boldsymbol{q}_{\boldsymbol{i}}$, which determines the natural logarithm base. In Eqs. (3) and (4), each constant has its physical sense. $\mathrm{B}=\mathrm{Ymax}$ is the limit of grain loss $(\mathrm{B} \leq$ $100 \%$ ). $\mathrm{C}$ is the dimensionless scale number, and $\mathrm{k}$ is the coefficient of intensity of increase of grain loss in portions per percent and $\mathrm{kg} / \mathrm{s}$.

Therefore, if two harvesters are compared, and one of them is reference and its $k b_{\text {red }}$ is lower than that of the second harvester, $\mathrm{kb}_{\mathrm{n}}$, then at equal outputs, the reference harvester is 
preferred, since under actual operation conditions upon variation of crop feed, it operates more steadily and its grain loss will be lower than, for instance, of the compared harvester. Hence, the second analytical criterion is expressed as follows:

$$
\lambda_{2}=\frac{k_{\text {new }}}{k_{\text {ref }}}=\frac{(k b)_{\text {new }}}{(k b)_{\text {ref }}}
$$

If $\lambda_{2}<1$, then the new harvester is better, if $\lambda_{2}>1$

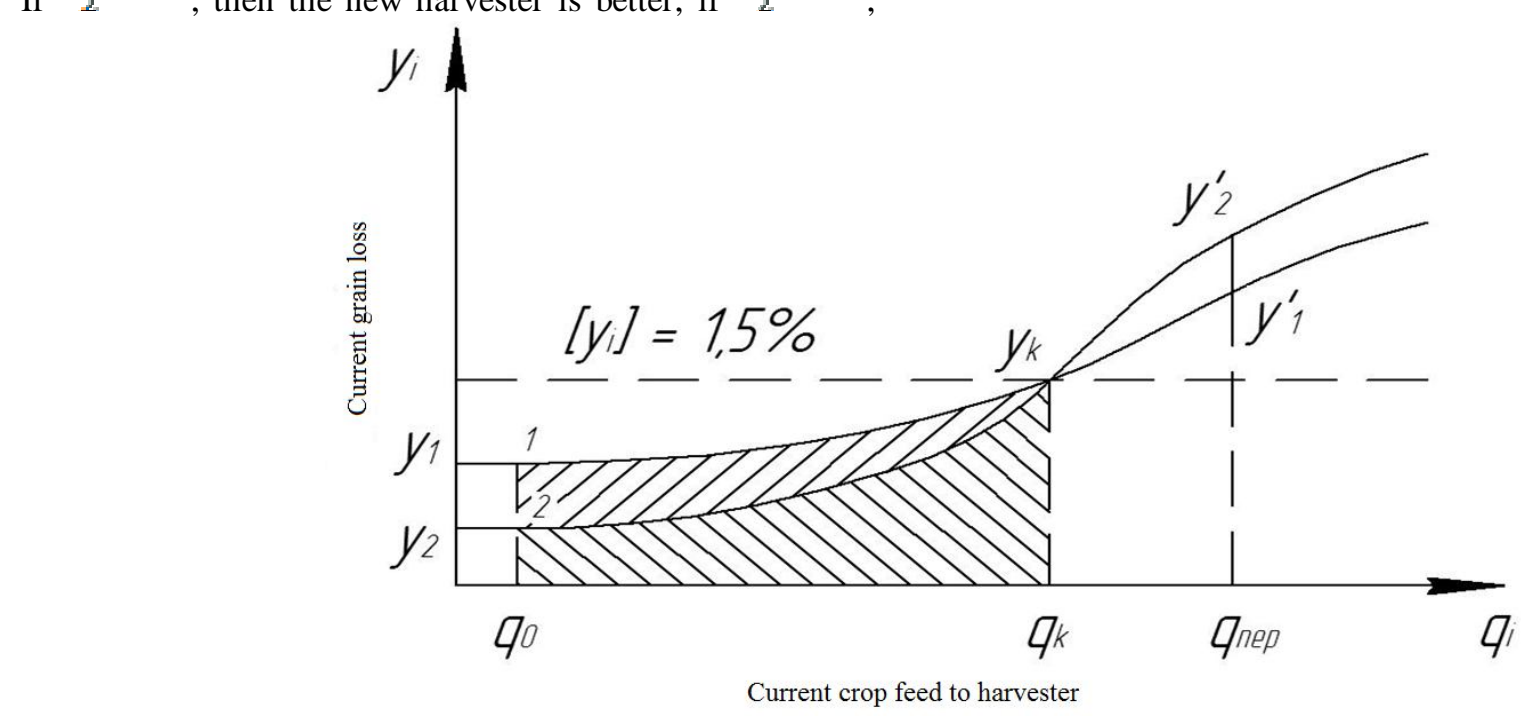

Figure 2: Estimated operation grain loss in harvester operation mode.

For instance, comparative tests are performed for two harvesters which demonstrate the same output (the point $\mathrm{q}_{\mathrm{k}}$ on abscissa), but the coefficient of intensity of grain loss for the first harvester $y_{1}$ is lower, and in terms of $\lambda_{2}$, it is, respectively, superior in comparison with the second harvester $\left(\mathrm{y}_{2}\right)$. However, the absolute grain loss by the first harvester in operation range of feed is higher than that of the second harvester $\left(\mathrm{y}_{1}>\mathrm{y}_{2}\right)$. So what? The answer to this then the reference harvester is preferred, since under actual operation conditions upon variation of crop feed, it operates more steadily and its grain loss will be lower.

The third analytical index is the operational grain loss in operation mode, when the current feed to harvester $\mathrm{q}_{i}$ is in the range of $\mathrm{q}_{\min } \leq \mathrm{q}_{\mathrm{i}} \leq \mathrm{q}_{\mathrm{k}}$. The necessity of this criterion is illustrated in Fig. 2. Let us explain it.

$$
\sum \bar{Y}=\int_{g_{\min }}^{g_{k}} \frac{b}{1+\operatorname{cexp}\left(-k b g_{i}\right)}=\frac{b}{k} l_{n} \frac{e^{k b g_{k}}+c}{e^{k b g_{\min }+c}}
$$

That is, we consider definite integral of Eq. (3) while varying crop feed from $\mathrm{q}_{\min }$ to $\mathrm{q}_{\mathrm{k}}$.

The third criterion of evaluation of grain loss upon comparison of two harvesters is defined as follows:

$$
\lambda_{3=\sum \bar{Y}_{2}}=\frac{\frac{b_{1}}{k_{1}} \ln \left[\frac{e^{k_{1} b_{1} q_{k_{1}+c}}}{e^{k_{1} b_{1} q_{m i n 1+C}}}\right]}{\frac{b_{2}}{k_{2}} \ln \left[\frac{e^{k_{2} b_{2} q_{k}+c}}{e^{k_{2} b_{2} q_{2} m i n+c}}\right]}
$$

Therefore, if $\lambda_{3}>1$, then the first harvester in feed operation range will provide higher grain loss, $\overline{\boldsymbol{Y}}_{1}$, than the question is given by the third criterion, which compares average integral grain loss by harvester in operation range of crop feed starting from certain initial feed, when the operation process of harvester becomes stable. For instance, for harvesters in the class of $5 \mathrm{~kg} / \mathrm{s}$ and above, it is as follows: $\mathrm{q}_{0}$ $\approx 1.5-2.0 \mathrm{~kg} / \mathrm{s}$.

Average integral grain loss in operation range of crop feed is determined as follows: 
E.V. Zhalnin et al., International Journal of Emerging Trends in Engineering Research, 8(9), September 2020, $6546-6552$

the norms. For instance, a harvester in operation mode can operate with grain loss of both $0.2 \%$ and $1.2 \%$ of the total amount of grain threshed and collected into tanker. These values seem to be moderate and they are lower than the norms. But these are grams of grain lost by the harvester each second. In one hour of continuous operation of the harvester, these grams are transformed into several kilograms and even into hundreds of kilograms during working day. Thus, it is important to know not only the loss absolute value (the third criterion), but also their closeness to the norms in harvester operation mode. Of course, the lower they are than the norms, the better it is. This index is analytically defined as follows:

$$
\varphi_{4}=\frac{[Y]-\Sigma Y_{p}}{[Y]}
$$

where $[Y]$ is the norm of grain loss, at which the harvester output is determined (1.5\%);

$\Sigma Y_{p}$ is the average integral grain loss at feeds in the range

from $g_{\min }$ to $g_{k}$ (Eq. 10).

The coefficient limits are: $0<\varphi_{4}<1$. Hence, the closer is $K_{2}$ to one, the lower is the loss by harvester in feed operation range. Therefore, this criterion provides qualitative evaluation of harvester operation and significantly supplements the third criterion: $\varphi_{3}$. The dynamics of the coefficient $\varphi_{4}$ are summarized in Table 1 at various values of average integral grain loss $\left[Y_{p}\right]$.

Table 1: $\varphi_{4}$ at various $\Sigma \bar{Y}_{\mathrm{p}}$

\begin{tabular}{|l|l|l|l|l|l|l|l|l|}
\hline $\begin{array}{l}\Sigma Y_{p} \\
\%\end{array}$ & 0.2 & 0.4 & 0.6 & 0.8 & 1.0 & 1.2 & 1.3 & 1.4 \\
\hline$\varphi_{4}$ & 0.86 & 0.73 & 0.6 & 0.46 & 0.38 & 0.2 & 0.13 & 0.07 \\
\hline
\end{tabular}

On this basis, the fourth criterion of evaluation of the compared harvesters is as follows:

$$
\lambda_{4}=\frac{\varphi_{4(\text { ref })}}{\varphi_{4(n e w)}}
$$

where $\varphi_{4(\text { ref }) \text { and }} \varphi_{4(\text { new })}$ are the coefficients for the reference and new harvester (or compared with the reference), respectively.

If $\lambda_{4}>1$, then the reference is better, if $\lambda_{4}<1$, then the compared harvester is better.

The fifth index and respective criterion determine average integral grain loss by the harvester in overload mode, that is, when the current crop feed to harvester is higher than the

output $g_{k}$. This mode of harvester operation under actual conditions is inevitable. There are no automatic means to restrict crop feed to harvester. Actual crop feed to harvester is a random value. In the course of actual harvester operation, all factors determining the crop feed to harvester are random. The working width of reaper cut is nearly always less than the designed specification in order to avoid skips. The yield of grain and straw along the pass distance can vary in the range of 0.8-1.6 of average for the field. Due to relief irregularities, the harvester speed also varies. In addition, harvester driver can be interested in operation at higher crop feeds, which increases the chance of harvester overload. Therefore, it is important to evaluate harvester operation in such modes: how stable the operation is, how intensive the loss increase is. Grain loss upon overload up to $30 \%$ from rated $\mathrm{q}_{\mathrm{k}}$ is determined as follows:

$$
\sum \bar{Y}_{\text {over }}=\int_{g_{k}}^{1.3 g_{k}} \frac{b}{1+\operatorname{cexp}\left(-k b g_{i}\right)}=\frac{b}{k} l_{n} \frac{e^{k b 1.3 g_{k}}+c}{e^{k b g_{\mathrm{n}}}+c} .
$$

Herewith, the fifth analytical evaluation criterion of harvesters, compared with the reference, is as follows:

$$
\lambda_{5}=\frac{\sum \bar{Y}_{\text {over.ref }}}{\sum \bar{Y}_{\text {overnew }}}
$$

Therefore, if $\lambda_{5}<1$, the reference harvester operates in overload mode with lower loss than the compared machine, for instance, new harvester. Respectively, if $\lambda_{5}>1$, the new harvester is better in terms of this criterion.

Ultimate load at the level of $1.3 \mathrm{q}_{\mathrm{k}}$ is stipulated by standard testing procedure of harvesters, according to which harvester should be tested also upon loads higher than the rated values by $25-30 \%$.
Table 2 summarizes generalized characteristic of the proposed indices of engineering level of harvesters and their evaluation criteria by tests in comparison with analog.

Each of the mentioned properties of harvester is its passport specification since it strictly reflects its design features. However, their values increase even higher, when it is required to compare different harvesters or, for instance, to evaluate a new harvester model in comparison with reference. Then these performances become similar criteria, presenting the ratio of respective performances of a new model to basic one.

Therefore, the proposed five analytical indices (Table 2) and respective analytical criteria make it possible to obtain more 
E.V. Zhalnin et al., International Journal of Emerging Trends in Engineering Research, 8(9), September 2020, $6546-6552$

detailed information after tests about general engineering level of harvester, peculiarities of its operation under actual operation conditions, and to select the best model, when a group of harvesters is tested under the same conditions.

Table 2: Analytical indices and evaluation criteria of engineering level of grain harvesters in comparison with reference on the basis of logistic dependence of grain loss on amount of threshed crops

\begin{tabular}{|c|c|c|c|}
\hline $\begin{array}{l}\text { Physical meaning of } \\
\text { harvester operation } \\
\text { indicator / symbol }\end{array}$ & Analytical expression of the indicator & $\begin{array}{l}\text { Physical } \\
\text { meaning of } \\
\text { criterion } \\
\text { symbol }\end{array}$ & $\begin{array}{l}\text { Analytical expression } \\
\text { of the criterion with } \\
\text { regard to reference }\end{array}$ \\
\hline 1 & 2 & 3 & 4 \\
\hline $\begin{array}{l}\text { Determines harvester } \\
\text { output } \mathrm{q}_{\mathrm{h}} \text { in terms of } \\
\text { normalized feed to } \\
\text { rated parameters of } \\
\text { grain loss, straw } \\
\text { amount, straw } \\
\text { moisture, and others / } \\
\varphi_{1}\end{array}$ & $\varphi=\frac{1}{b b} l_{n}\left[\frac{[y] \cdot \varepsilon}{b-[y]}\right] \cdot\left[\frac{1+\alpha_{\phi}}{1+u_{n o r}}\right] \cdot\left[\frac{100-w_{n a r m}}{100-w_{o c t}}\right]$ & $\begin{array}{l}\text { Compares } \\
\text { harvester } \\
\text { outputs / } \lambda 1\end{array}$ & $\lambda_{1}=\frac{\varphi_{1 \mathrm{MNN}}}{\varphi_{1 \mathrm{vef}}}$ \\
\hline $\begin{array}{l}\text { Determines intensity } \\
\text { of increase in grain } \\
\text { loss of harvester with } \\
\text { increase in crop feed / } \\
\varphi_{2}\end{array}$ & $\phi_{2}=k b$ & $\begin{array}{l}\text { Compares } \\
\text { coefficients of } \\
\text { intensity of } \\
\text { increase in } \\
\text { grain loss with } \\
\text { increase in crop } \\
\text { feed } / \lambda_{2}\end{array}$ & $\lambda_{1}=\frac{\varphi_{2 \operatorname{men}}}{\varphi_{2 v f f}}=\frac{(k b)_{n \in W}}{(k b)_{r s f}}$ \\
\hline $\begin{array}{l}\text { Determines average } \\
\text { integral grain loss by } \\
\text { harvesters in its } \\
\text { operation mode, that } \\
\text { is, in the feed range } \\
q_{\operatorname{mim}} \leq q_{i} \leq q_{\text {nnmm }} / \varphi_{3}\end{array}$ & 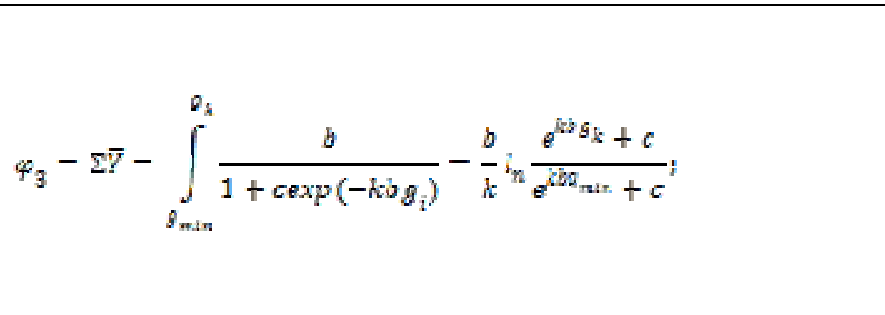 & $\begin{array}{lr}\text { Compares } \\
\text { average } \\
\text { integral grain } \\
\text { loss } \\
\text { harvester } \\
\text { operation mode } \\
/ \lambda_{3}\end{array}$ & 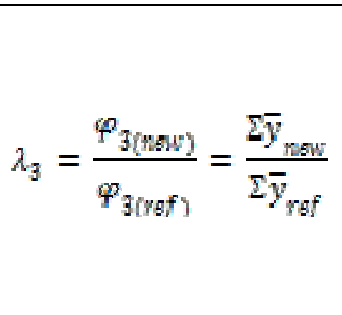 \\
\hline $\begin{array}{l}\text { Determines the ratio of } \\
\text { current grain loss in } \\
\text { harvester operation } \\
\text { mode to rated } / \varphi_{4}\end{array}$ & $\varphi_{4}=\frac{[y]-\Sigma \bar{y}_{p}}{[y]}$ & $\begin{array}{l}\text { Compares } \\
\text { current grain } \\
\text { loss with regard } \\
\text { to rated level in } \\
\text { operation mode } \\
\text { of compared } \\
\text { harvesters } / \lambda_{4} \\
\end{array}$ & $\lambda_{4}=\frac{\varphi_{4(n w)}}{\varphi_{4(m f)}}$ \\
\hline $\begin{array}{l}\text { Determines average } \\
\text { integral grain loss in } \\
\text { overload mode of } \\
\text { harvester operation, } \\
\text { that is, when } \\
q_{\text {m,ng, }} \leq q_{5} \leq 1.3 q_{\text {mmon }} \\
/ \varphi_{5}\end{array}$ & $\varphi_{5}=\Sigma \bar{V}=\int_{q_{\min }}^{1.3_{g_{k}}} \frac{b}{1+\operatorname{cexp}\left(-k b g_{i}\right)}=\frac{b}{k} \frac{\exp \left(h b 1.3 q_{\text {hank }}\right) \| c}{\exp \left(k b q_{\text {hurv }}\right)+z}$ & $\begin{array}{l}\text { Compares } \\
\text { average } \\
\text { integral grain } \\
\text { loss in overload } \\
\text { operation mode } \\
\text { of compared } \\
\text { harvesters } / \lambda_{5}\end{array}$ & $\lambda_{\xi=}=\frac{\varphi_{5 \text { (new) }}}{\varphi_{5(\text { sef })}}$ \\
\hline
\end{tabular}

\section{CONCLUSION}

1. Five new analytical evaluation indices of engineering level of grain harvesters are proposed based on analysis of operating performance of threshing machine and harvester: The first index, $\varphi_{1}$, determines the harvester output and the rate of consistency of harvester parameters in its class in terms of output.

The second index, $\varphi_{2}$, determines the intensity of increase in grain loss with the increase in crop feed.

The third index, $\varphi_{3}$, characterizes average integral grain loss in harvester operation mode in the range of 
E.V. Zhalnin et al., International Journal of Emerging Trends in Engineering Research, 8(9), September 2020, $6546-6552$

$$
g_{\min }<g_{i}<g_{\text {new }} .
$$

The fourth index, $\varphi_{4}$, determines the ratio of actual grain loss in harvester operation mode to rated loss.

The fifth index, $\varphi_{5}$, estimates average integral grain loss by harvester in overload modes, that is, when the feed to harvester is higher than its output in the range of $g_{k}<\varphi_{i}<1.3 g_{k}$.

2. Each index $\varphi_{\mathrm{i}}$ corresponds to criterion $\lambda_{\mathrm{i}}$ as the ratio of respective indices for reference harvester and compared harvester.

3. The proposed analytical criteria reflect individual engineering and design ability of each harvester; thus, they can be used as its specification.

4. In order to improve the information content of test results of grain harvesters of various models and to provide objective evaluation of their engineering level in comparison between them and with reference model, it is recommended to evaluate harvesters by the five analytical indices and respective criteria.

\section{REFERENCES}

1. Industrial standard OST 70.8.1-81 Testing agricultural machinery. Grain harvesters. Schedule and methods of tests.

2. R.K. Chaab, S.H. Karparvarfard, H. Rahmanian-Koushkaki, A. Mortezaei, M. Mohammadi, Predicting header wheat loss in a combine harvester, a new approach, Journal of the Saudi Society of Agricultural Sciences, vol. 19, no. 2, pp. 179-184, 2020.

3. L. Špokas, V. Adamčuk, V. Bulgakov, L. Nozdrovický, The experimental research of combine harvesters, Research in Agricultural Engineering, no. 62, pp. 106-112, 2016.

4. M. Eimer, Einfluss von Schnittzeitpunkt und Feuchte des Erntegutes auf die Arbeitsqualität des Schlagleistendreschwerks, In: VDI/MEG Kolloquium Landtechnik. Mähdrescher, April 25-26, 1988, Hohenheim, pp. 93-106, 1988.

5. Z. Kelemen, J. Komladi, V. Petö, Der Verlauf der Durchsatzleistung, der Kornverluste und des Treibstoffverbrauches bei Mähdreschern unterschiedlicher Konstruktion in der Weizenernte, Tagungsband VDI - MEG Kolloquium Landtechnik, Mähdrescher, pp. 117-124, 2005.

6. P. Wacker, Untersuchungen zum Dresch - und Trennvorgang von Getreide in einem Axialdreschwerk. Forschungsbericht Agrartechnikder MEG, pp. 117-119, 1985.

7. P. Wacker, Einfluß von Stoffeigenschaften auf die Mähdruscheignung von Körnerfrüchten, Engineering, Research Papers of Lithuanian University of Agriculture, vol. 6, no. 1, pp. 21-26, 2003.

8. T. Rademacher, Mähdrescher. Die Qual der richtigen Wahl, Getreide Magazin, no. 3, pp. 186-191, 2003.
9. V.V. Baev, V.S. Chupilko, Integral'naya krivaya dlya opredeleniya nominal'noi proizvoditel'nosti zernouborochnykh kombainov [Integral curve to determine rated output of grain harvesters]: Collected works: Methods and means of test facilities of agricultural machinery. Novokubansk, 1999.

10. E.V. Zhalnin, Poteri zerna za molotilkoi kombaina kak funktsiya podachi [Grain loss by threshing machine as a function of feed], Mekhanizatsiya $i$ elektrifikatsiya sots. sel'skogo khozyaistva, no. 8, pp. 6-8, 1976.

11. M. Šotnar, J. Pospíšil, J. Mareček, T. Dokukilová, V. Novotný, Influence of the Combine Harvester Parameter Settings on Harvest Losses, Acta Technologica Agriculturae, vol. 21, no. 3, pp. 105-108, 2018.

12. A.A. Almosawi, Combine harvester header losses as affected by reel and cutting indices, Plant Archives, no. 19, pp. 203-207, 2019. 